\title{
GROWTH AND HAEMOLYTIC ACTIVITY OF PATHOGENIC VIBRIO SPECIES IN EGG-FRIED-RICE WITH DIFFERENT EGG RATIOS
}

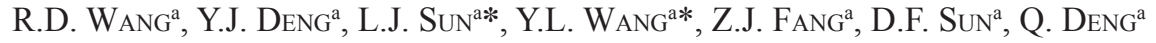 \\ and R. GOONERATNE

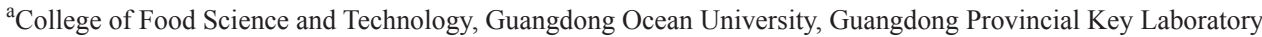 \\ of Aquatic Product Processing and Safety, Key Laboratory of Advanced Processing of Aquatic Products of \\ Guangdong Higher Education Institution 524088. China \\ ${ }^{\mathrm{b}}$ Department of Wine, Food and Molecular Biosciences, Faculty of Agriculture and Life Sciences, Lincoln \\ University, Lincoln 7647, Canterbury. New Zealand
}

(Received: 10 July 2018; accepted: 2 October 2018)

Growth and haemolytic activity of several pathogenic Vibrio species were compared in egg-fried-rice with different egg ratios. Egg-fried-rice preparations with rice-to-egg ratios of 4:1, 1:1, and 1:4 were inoculated with either Vibrio parahaemolyticus, V. cholerae, V. vulnificus, or V. alginolyticus and incubated for $24 \mathrm{~h}$. Cell number, thermostable direct haemolysin (TDH) activity, and total haemolytic activity were determined. The cell number and total haemolytic activity increased in all Vibrio strains after $24 \mathrm{~h}$, and these were most marked in egg-fried-rice with the highest egg content $(1: 4$ (rice:egg) ratio; $\mathrm{P}<0.05)$. V. alginolyticus exhibited the maximal growth and $V$. parahaemolyticus the highest haemolytic activity, but only V. parahaemolyticus ATCC 33847 , V. alginolyticus CAMT 21162, and V. alginolyticus HY 91101 showed TDH activity. Results suggest that lowering egg content in egg-fried-rice could reduce growth and virulence of Vibrio pathogens.

Keywords: egg-fried-rice, growth, pathogenic Vibrio species, thermostable direct haemolysin activity, total haemolytic activity

Vibrio species are Gram-negative bacteria that occur in coastal waters and maintain ecological balance in the marine environment. Of all Vibrio species, V.cholerae (Vc), V. parahaemolyticus $(V p), V$. alginolyticus (Va), and V. vulnificus ( $V v)$ are human pathogens (Bowers \& Depaola, 2010). Consumption of seafood contaminated with pathogenic Vibrio spp. may cause acute gastroenteritis characterized by diarrhoea, vomiting, abdominal cramps, and systemic infections (JANDA et al., 1988). Some Vibrio spp. (e.g. Vp) can contaminate seafood and also non-seafood such as poultry, pork, eggs, and associated food such as egg-fried-rice by cross contamination and/or via cooking utensils (TunUNG et al., 2010; Wu et al., 2014; XIE et al., 2016). However, little is known about the pathogenicity of Vibrio spp. in non-seafood.

All pathogenic Vibrio spp. produce haemolysins, with thermostable direct haemolysin (TDH) regarded as the most important virulence factor (HoNDA \& IIDA, 1993). WANG and coworkers $(2016,2018)$ compared the pathogenicity of $V p$ in food matrices, and found that growth rate and haemolytic activity were significantly higher in egg-fried-rice, indicating a possible higher risk of $V p$ occurrence in this food. It is not known, however, whether the

\footnotetext{
* To whom correspondence should be addressed.

Phone: + 861376309 4052; e-mails: suncamt@126.com (L.S.), wangylchina@163.com (Y.W.).
} 
growth and haemolytic activity of $V p$ changes with the proportion of egg in egg-fried-rice. Neither is it known whether growth and haemolytic activity are different for other pathogenic Vibrio spp. in egg-fried-rice.

The objectives of this study are to quantify the growth, haemolytic activity, and pathogenicity of 12 strains of four Vibrio spp., namely, $V p, V c, V a$ and $V v$, in egg-fried-rice with different egg ratios.

\section{Materials and methods}

\subsection{Bacterial strains and growth conditions}

V. parahaemolyticus strains ATCC 17802 and ATCC 33847 were obtained from the China Committee for Culture Collection of Microorganisms. Vp (ZJS-Vp-3), Vc (VC 13130, VC 13131 and VC 13132), Va (VA 12021, CAMT 21162 and HY 91101), and $V v$ (VV 13009, VV 13010, and VV 13011) were isolated from diseased shrimp, fish, and mussel. All strains were verified (using PCR reactions for amplification of a hypervariable region of the 16S rRNA gene) and stored in $25 \%$ glycerol at $-20{ }^{\circ} \mathrm{C}$. Each strain was grown in brain heart infusion broth (BLBT, Beijing, China) containing $3 \% \mathrm{NaCl}$ at $37^{\circ} \mathrm{C}$ for $24 \mathrm{~h}$, and the inoculum was three times passaged in the broth. The final concentrations of inoculants were adjusted to $\sim 10^{5}$ colony-forming units $(\mathrm{CFU}) \mathrm{ml}^{-1}$ for inoculation of egg-fried-rice matrices.

\subsection{Egg-fried-rice preparation and inoculation}

The egg-fried-rice was prepared in the laboratory according to WANG and co-workers (2016). Briefly, egg-fried-rice with different ratios of rice to egg $(\mathrm{wt} / \mathrm{wt}=4: 1,1: 1,1: 4)$ were cooked at $80{ }^{\circ} \mathrm{C}$ for $20 \mathrm{~min}$. Test portions $(100 \mathrm{~g}, \mathrm{n}=3)$ of egg-fried-rice, with salt added at $3 \%$ in sterile Erlenmeyer flasks, were sterilized by autoclave (YXQ-L-50A, Shanghai Boxun, Shanghai, China) at $100^{\circ} \mathrm{C}$ for $20 \mathrm{~min}$ to kill native bacteria, then transferred to a biosafety hood, cooled to room temperature, inoculated with $1 \mathrm{ml}$ of pathogenic Vibrio spp., and vortexed (XW-80A, Qilinbei, Haimen, China) for $10 \mathrm{~min}$. A $10 \mathrm{~g}$ sample of each inoculated test portion was analysed by the plate count method (JONGENBURGER et al., 2010) to obtain an initial bacterial count. The bacteria were serially diluted and grown in thiosulphate citrate bile salts sucrose agar medium to form individual colonies, which were quantified (colonyforming units, CFUs). The remainder of the inoculated samples were incubated at $37^{\circ} \mathrm{C}$ for $24 \mathrm{~h}$.

After incubation, the inoculated food samples $(90 \mathrm{~g})$ were divided into two parts. One part (10 g) was used for bacterial quantification (as described above), and the other $(80 \mathrm{~g})$ was washed with $80 \mathrm{ml}$ of $0.01 \mathrm{M}$ phosphate-buffered saline (PBS, pH 7.2) and centrifuged (Thermo Lynx 6000, Thermo Scientific, Waltham, MA) at 12000 r.p.m. for 20 min at $4{ }^{\circ} \mathrm{C}$. The supernatant was filtered $\left(0.22 \mu \mathrm{m}\right.$, Millipore, Billerica, MA) and stored at $-20{ }^{\circ} \mathrm{C}$ until used to test haemolytic activity.

The same procedure was used for control samples of the different egg ratios of eggfried-rice except not inoculated with the pathogenic Vibrio spp.

\subsection{Haemolysin production}

1.3.1. TDH activity. TDH activity was determined as described by WAGATSUMA (1968), with slight modification. The test plate consisted of 5\% rabbit red blood cells (RBCs) in Wagatsuma 
agar medium (BLBT). Once the blood agar solidified in the plate, wells were made in the agar. Then, $50 \mu \mathrm{l}$ of filtrate was added to each well and cultured for $12 \mathrm{~h}$ at $37{ }^{\circ} \mathrm{C}$. The diameter of the lytic halo around each well was considered a positive reaction for detecting the extent of TDH activity.

1.3.2. Total haemolytic activity. Total haemolytic activity of egg-fried-rice filtrates was measured by the relative haemolytic activity assay (GARCIA-ARRIBAS \& KRAMER, 1990). Briefly, rabbit haemocytes were obtained by centrifugation of blood (3500 r.p.m., $4{ }^{\circ} \mathrm{C}, 10$ min), washed three times with PBS, and diluted to 5\% with PBS. Subsequently, a sample $(400 \mu \mathrm{l})$ of filtrates was mixed with $100 \mu \mathrm{l}$ of $5 \%$ rabbit RBC in $1.5-\mathrm{ml}$ sterile tubes and incubated at $37^{\circ} \mathrm{C}$ for $1.5 \mathrm{~h}$. Unlysed RBCs were allowed to settle to the bottom of the tube overnight at $4{ }^{\circ} \mathrm{C}$, and 200 - $\mu$ l portions of the supernatant were transferred to 96 -well flatbottomed microplates (Nunc, Thermo Scientific, Waltham, MA), and the absorbance was measured at $570 \mathrm{~nm}$ in a microplate reader (Varioskan Flash, Thermo Scientific). The same procedure was employed for controls, except for the samples consisting of only egg-friedrice filtrates without the pathogenic Vibrio spp. inoculum. The results are reported as:

$$
\mathrm{A}_{\text {relative haemolytic activity }}=\mathrm{A}_{\text {sample }}-\mathrm{A}_{\text {control }} \text {. }
$$

\subsection{Statistical analysis}

All data were analysed using SPSS 19.0 software (SPSS Inc., Chicago, IL, USA). Differences between the means were tested by one-way ANOVA, with the level of significance set at $\mathrm{P}<0.05$.

\section{Results and discussion}

\subsection{Growth of pathogenic Vibrio spp. in egg-fried-rice}

Egg-fried-rice can be contaminated by many microbes including Salmonella and Listeria spp. Invasive infections often develop after consumption of aquatic food contaminated by Vibrio spp., but there are no reports of the pathogenicity of Vibrio spp. in non-aquatic food. In this study, we showed that pathogenic Vibrio spp. can grow in egg-fried-rice with different egg ratios $(\mathrm{P}<0.05$, Table 1). Among the pathogenic Vibrio spp., Va exhibited the highest growth. It is now clear that egg-fried-rice can provide the nutrients required for Vibrio spp. growth and that infected egg-fried-rice may also account for some Vibrio spp. outbreaks. This finding is in agreement with reports of non-seafood-borne illnesses caused by Vp. through cross-contamination of cooked foods (SCIENTIFIC CommitTeE on Enteric Infections and Foodborne Diseases, 2011). Thus, Vibrio spp. growth in egg-fried-rice can be prevented by avoiding cross contamination of ready-to-eat foods with uncooked food or food utensils and by stepping up ready-to-eat food surveillance/monitoring.

Significantly higher $(\mathrm{P}<0.05)$ growth of pathogenic Vibrio spp. were observed in eggfried-rice with a high egg:rice ratio (4:1) compared with a low egg:rice ratio (1:4). CHIANG and $\mathrm{CHOU}$ (2008) indicated that the growth and toxin production of $V p$ can be augmented by increasing the nitrogen source (protein) in the medium. Protein is one of the main nutrients in eggs. So, when the egg ratio in fried rice is increased, the protein content is also increased. We hypothesize that the high protein content in egg-fried-rice promoted the growth of $V p$. Other pathogenic Vibrio species ( $V c, V v$, and $V a$ ) behaved similarly, with higher growth rate in fried rice with a higher egg:rice ratio. It appears that all pathogenic Vibrio spp. may have a similar demand of protein for growth. 
Table 1. Growth of 12 pathogenic strains of Vibrio species in egg-fried-rice with different egg ratios ${ }^{*}$

\begin{tabular}{|c|c|c|c|c|c|}
\hline \multirow{2}{*}{$\begin{array}{l}\text { Rice:egg } \\
(w / w)\end{array}$} & \multirow[t]{2}{*}{ Vibrio spp. } & \multirow[t]{2}{*}{ Strains } & \multicolumn{3}{|c|}{ Cell number in egg-fried-rice $\left(\lg \mathrm{CFU} \cdot \mathrm{g}^{-1}\right) \pm \mathrm{SD}$} \\
\hline & & & Initial & Final & Growth $^{+}$ \\
\hline \multirow{12}{*}{$4: 1$} & Vibrio parahaemolyticus & ATCC 17802 & $2.92 \pm 0.31$ & $7.21 \pm 0.41$ & $4.29 \pm 0.51^{b}$ \\
\hline & & ATCC 33847 & $2.83 \pm 0.22$ & $7.32 \pm 0.23$ & $4.49 \pm 0.36^{\mathrm{b}}$ \\
\hline & & ZJS-Vp-3 & $2.36 \pm 0.24$ & $7.18 \pm 0.33$ & $4.82 \pm 0.34^{\mathrm{c}}$ \\
\hline & Vibrio cholerae & VC 13130 & $2.85 \pm 0.20$ & $7.41 \pm 0.33$ & $4.56 \pm 0.42^{\mathrm{c}}$ \\
\hline & & VC 13131 & $2.82 \pm 0.19$ & $7.23 \pm 0.28$ & $4.41 \pm 0.22^{\mathrm{c}}$ \\
\hline & & VC 13132 & $2.79 \pm 0.22$ & $7.30 \pm 0.30$ & $4.51 \pm 0.26^{\mathrm{b}}$ \\
\hline & Vibrio alginolyticus & VA 12021 & $2.48 \pm 0.19$ & $7.53 \pm 0.25$ & $5.05 \pm 0.24^{\mathrm{c}}$ \\
\hline & & CAMT 21162 & $2.77 \pm 0.26$ & $7.79 \pm 0.30$ & $5.02 \pm 0.33^{\mathrm{c}}$ \\
\hline & & HY 91106 & $2.21 \pm 0.45$ & $7.45 \pm 0.16$ & $5.24 \pm 0.39^{\mathrm{c}}$ \\
\hline & Vibrio vulnificus & VV 13009 & $2.99 \pm 0.22$ & $7.42 \pm 0.12$ & $4.43 \pm 0.28^{\mathrm{c}}$ \\
\hline & & VV 13010 & $2.44 \pm 0.50$ & $7.38 \pm 0.22$ & $4.94 \pm 0.13^{\mathrm{c}}$ \\
\hline & & VV 13011 & $2.56 \pm 0.48$ & $7.44 \pm 0.36$ & $4.88 \pm 0.32^{\mathrm{b}}$ \\
\hline \multirow{12}{*}{$1: 1$} & Vibrio parahaemolyticus & ATCC 17802 & $2.81 \pm 0.12$ & $8.21 \pm 0.16$ & $5.40 \pm 0.33^{\mathrm{a}}$ \\
\hline & & ATCC 33847 & $2.92 \pm 0.26$ & $8.30 \pm 0.20$ & $5.38 \pm 0.36^{\mathrm{a}}$ \\
\hline & & ZJS-Vp-3 & $2.88 \pm 0.26$ & $8.20 \pm 0.10$ & $5.32 \pm 0.22^{\mathrm{b}}$ \\
\hline & Vibrio cholerae & VC 13130 & $2.77 \pm 0.35$ & $8.28 \pm 0.17$ & $5.51 \pm 0.31^{\mathrm{a}}$ \\
\hline & & VC 13131 & $2.84 \pm 0.23$ & $8.33 \pm 0.20$ & $5.49 \pm 0.34^{\mathrm{a}}$ \\
\hline & & VC 13132 & $2.67 \pm 0.31$ & $8.41 \pm 0.23$ & $5.74 \pm 0.27^{\mathrm{a}}$ \\
\hline & Vibrio alginolyticus & VA 12021 & $2.69 \pm 0.17$ & $8.81 \pm 0.12$ & $6.12 \pm 0.33^{\mathrm{b}}$ \\
\hline & & CAMT 21162 & $2.94 \pm 0.19$ & $8.73 \pm 0.23$ & $5.79 \pm 0.39^{b}$ \\
\hline & & HY 91106 & $2.51 \pm 0.26$ & $8.80 \pm 0.19$ & $6.29 \pm 0.27^{\mathrm{a}}$ \\
\hline & Vibrio vulnificus & VV 13009 & $2.90 \pm 0.21$ & $8.23 \pm 0.10$ & $5.33 \pm 0.30^{\mathrm{b}}$ \\
\hline & & VV 13010 & $2.79 \pm 0.32$ & $8.30 \pm 0.13$ & $5.51 \pm 0.35^{\mathrm{b}}$ \\
\hline & & VV 13011 & $2.63 \pm 0.16$ & $8.11 \pm 0.11$ & $5.48 \pm 0.28^{\mathrm{a}}$ \\
\hline \multirow{12}{*}{$1: 4$} & Vibrio parahaemolyticus & ATCC 17802 & $2.61 \pm 0.38$ & $8.41 \pm 0.26$ & $5.80 \pm 0.40^{\mathrm{a}}$ \\
\hline & & ATCC 33847 & $2.98 \pm 0.40$ & $8.39 \pm 0.19$ & $5.41 \pm 0.32^{\mathrm{a}}$ \\
\hline & & ZJS-Vp-3 & $2.58 \pm 0.28$ & $8.39 \pm 0.16$ & $5.81 \pm 0.16^{\mathrm{a}}$ \\
\hline & Vibrio cholerae & VC 13130 & $2.84 \pm 0.30$ & $8.09 \pm 0.12$ & $5.25 \pm 0.24^{\mathrm{b}}$ \\
\hline & & VC 13131 & $2.65 \pm 0.11$ & $8.47 \pm 0.22$ & $5.82 \pm 0.31^{\mathrm{a}}$ \\
\hline & & VC 13132 & $2.82 \pm 0.25$ & $8.51 \pm 0.40$ & $5.69 \pm 0.28^{\mathrm{a}}$ \\
\hline & Vibrio alginolyticus & VA 12021 & $2.89 \pm 0.19$ & $8.93 \pm 0.31$ & $6.04 \pm 0.26^{\mathrm{a}}$ \\
\hline & & CAMT 21162 & $2.92 \pm 0.22$ & $9.00 \pm 0.33$ & $6.08 \pm 0.28^{\mathrm{a}}$ \\
\hline & & HY 91106 & $2.81 \pm 0.24$ & $9.07 \pm 0.25$ & $6.26 \pm 0.30^{\mathrm{a}}$ \\
\hline & Vibrio vulnificus & VV 13009 & $2.66 \pm 0.14$ & $8.33 \pm 0.12$ & $5.67 \pm 0.26^{\mathrm{a}}$ \\
\hline & & VV 13010 & $2.94 \pm 0.23$ & $8.40 \pm 0.34$ & $5.46 \pm 0.29^{\mathrm{a}}$ \\
\hline & & VV 13011 & $2.71 \pm 0.30$ & $8.27 \pm 0.21$ & $5.56 \pm 0.31^{\mathrm{a}}$ \\
\hline
\end{tabular}

Note: Same-strain growth means where the three egg:rice ratios in the same strain have different superscript letters growth was significantly different $(\mathrm{P}<0.05)$.

${ }^{*}$ Mean \pm standard deviation of three replicates.

${ }^{+}$Growth $=$Final - Initial $\left(\log \mathrm{CFU} \cdot \mathrm{g}^{-1}\right)$ 


\subsection{Haemolysin production of pathogenic Vibrio spp. in egg-fried-rice}

Haemolysins control haemolytic activity, cytotoxicity, and enterotoxicity. TDH activity determines pathogenicity of Vibrio spp. (NISHIBUCHI \& KAPER, 1995). In the TDH activity test, only the strains Vp ATCC 33847, Va CAMT 21162, and Va HY 91101 showed $\beta$-haemolysis of rabbit RBC on blood agar (Table 2), indicating that not all pathogenic Vibrio spp. can produce TDH. As TDH is encoded by $t d h$ genes, we presumed that the Va CAMT 21162 and $V a$ HY 91101 strains may also be harbouring $t d h$ genes like the standard strain of Vp ATCC 33847. This result is consistent with findings of TANiguchi (1985) and THEETHAKAEW (2013) and their co-workers, who reported that very few isolated Vibrio spp. strains have TDH activity and only the Vibrio spp. strains isolated from clinical cases show TDH activity. The haemolytic zone of strains Vp ATCC 33847, Va CAMT 21162, and Va HY 91101 in our study significantly increased $(\mathrm{P}<0.05$, Table 2$)$ in high egg ratio fried-rice (rice:egg=1:4) filtrates of Vibrio spp. than in the low (rice:egg=4:1) and equal ratio (rice:egg=1:1) filtrates. We hypothesize that the foods with high egg content may stimulate the Vibrio spp. strains that harbour the $t d h$ genes to produce more TDH haemolysin and thereby increase the risk of food poisoning in all food types with a high egg content.

Total haemolytic activity reflects the degree of harm caused by Vibrio spp. virulence factors. All Vibrio spp. tested exhibited haemolytic activity (Table 2) with Vp $>V a$. No significant haemolytic activity was detected among $V c$ and $V v$. We believe that people consuming $V p$-contaminated egg-fried-rice will be affected more than those exposed to other Vibrio spp.

When the different egg ratios were compared, the highest haemolytic activity was observed in egg-fried-rice with the highest egg ratio (rice:egg=1:4). TANIGUCHI (1986) and SHINODA (1991) and their co-workers showed that production of lecithin dependent haemolysin, which causes haemolysis, increased at a higher lecithin concentration in the medium. IUCHI \& TANAKA (1980) reported that virulence factors of Vibrio spp. were repressed by the various carbohydrates present in the medium. We believe that the high concentration of carbohydrates in low-egg-ratio (rice:egg=4:1) egg-fried-rice may have suppressed the Vibrio species' ability to secrete exoenzymes with haemolytic activity. At higher egg ratios in fried-rice, the lecithin concentration was increased, and it may have stimulated the pathogenic Vibrio spp. to produce more lecithin-dependent haemolysin and hence exhibit greater haemolytic activity.

\section{Conclusions}

Pathogenic Vibrio spp. exhibited increased growth and total haemolytic activity in egg-friedrice. The highest growth was observed in Va strains and the highest haemolytic activity in $V p$ strains. The growth and haemolytic activity of pathogenic Vibrio spp. were influenced by the egg ratio in egg-fried-rice. Low egg ratios (high rice content) could limit growth and virulence factor production. High egg ratios not only significantly stimulated pathogenic Vibrio spp. to grow but also increased the TDH activity and total haemolytic activity.

This work was supported by the National Science Fund [No. 31371746]. 
Table 2. Haemolytic circle diameter and total haemolytic activity of 12 pathogenic strains of Vibrio species in eggfried-rice with different egg ratios*

\begin{tabular}{|c|c|c|c|c|}
\hline $\begin{array}{l}\text { Rice:egg } \\
(\mathrm{w} / \mathrm{w})\end{array}$ & Vibrio spp. & Strains & $\begin{array}{c}\text { Haemolytic zone } \\
\text { diameter }(\mathrm{mm}) \pm \mathrm{SD}\end{array}$ & $\begin{array}{c}\text { Total haemolytic } \\
\text { activity }\left(\mathrm{OD}_{570}\right) \pm \mathrm{SD}\end{array}$ \\
\hline \multirow{12}{*}{$4: 1$} & \multirow[t]{3}{*}{ Vibrio parahaemolyticus } & ATCC 17802 & - & $0.93 \pm 0.04^{\mathrm{c}}$ \\
\hline & & ATCC 33847 & $11.88 \pm 3.03^{\mathrm{b}}$ & $0.91 \pm 0.06^{\mathrm{c}}$ \\
\hline & & ZJS-Vp-3 & - & $0.88 \pm 0.13^{\mathrm{c}}$ \\
\hline & \multirow[t]{3}{*}{ Vibrio cholerae } & VC 13130 & - & $0.48 \pm 0.16^{\mathrm{c}}$ \\
\hline & & VC 13131 & - & $0.46 \pm 0.09^{\mathrm{c}}$ \\
\hline & & VC 13132 & - & $0.47 \pm 0.14^{\mathrm{c}}$ \\
\hline & \multirow[t]{3}{*}{ Vibrio alginolyticus } & VA 12021 & - & $0.60 \pm 0.03^{\mathrm{c}}$ \\
\hline & & CAMT 21162 & $7.01 \pm 1.89^{\mathrm{c}}$ & $0.62 \pm 0.08^{\mathrm{c}}$ \\
\hline & & HY 91106 & $6.21 \pm 2.45^{\mathrm{c}}$ & $0.63 \pm 0.04^{\mathrm{c}}$ \\
\hline & \multirow[t]{3}{*}{ Vibrio vulnificus } & VV 13009 & - & $0.52 \pm 0.05^{\mathrm{c}}$ \\
\hline & & VV 13010 & - & $0.51 \pm 0.10^{\mathrm{c}}$ \\
\hline & & VV 13011 & - & $0.54 \pm 0.12^{\mathrm{c}}$ \\
\hline \multirow{12}{*}{$1: 1$} & \multirow[t]{3}{*}{ Vibrio parahaemolyticus } & ATCC 17802 & - & $1.11 \pm 0.03^{\mathrm{b}}$ \\
\hline & & ATCC 33847 & $12.30 \pm 2.22^{\mathrm{b}}$ & $1.20 \pm 0.07^{\mathrm{b}}$ \\
\hline & & ZJS-Vp-3 & - & $1.15 \pm 0.09^{\mathrm{b}}$ \\
\hline & \multirow[t]{3}{*}{ Vibrio cholerae } & VC 13130 & - & $0.62 \pm 0.11^{\mathrm{b}}$ \\
\hline & & VC 13131 & - & $0.65 \pm 0.10^{\mathrm{b}}$ \\
\hline & & VC 13132 & - & $0.69 \pm 0.06^{\mathrm{b}}$ \\
\hline & \multirow[t]{3}{*}{ Vibrio alginolyticus } & VA 12021 & - & $0.82 \pm 0.04^{b}$ \\
\hline & & CAMT 21162 & $7.56 \pm 1.11^{b}$ & $0.83 \pm 0.04^{\mathrm{b}}$ \\
\hline & & HY 91106 & $7.62 \pm 2.32^{\mathrm{b}}$ & $0.86 \pm 0.03^{\mathrm{b}}$ \\
\hline & \multirow[t]{3}{*}{ Vibrio vulnificus } & VV 13009 & - & $0.63 \pm 0.06^{\mathrm{b}}$ \\
\hline & & VV 13010 & - & $0.70 \pm 0.12^{\mathrm{b}}$ \\
\hline & & VV 13011 & - & $0.65 \pm 0.06^{\mathrm{b}}$ \\
\hline \multirow{12}{*}{$1: 4$} & \multirow[t]{3}{*}{ Vibrio parahaemolyticus } & ATCC 17802 & - & $1.34 \pm 0.06^{\mathrm{a}}$ \\
\hline & & ATCC 33847 & $14.16 \pm 1.10^{\mathrm{a}}$ & $1.39 \pm 0.09^{\mathrm{a}}$ \\
\hline & & ZJS-Vp-3 & - & $1.30 \pm 0.03^{\mathrm{a}}$ \\
\hline & \multirow[t]{3}{*}{ Vibrio cholerae } & VC 13130 & - & $0.83 \pm 0.05^{\mathrm{a}}$ \\
\hline & & VC 13131 & - & $0.87 \pm 0.08^{\mathrm{a}}$ \\
\hline & & VC 13132 & - & $0.84 \pm 0.06^{\mathrm{a}}$ \\
\hline & \multirow[t]{3}{*}{ Vibrio alginolyticus } & VA 12021 & - & $0.99 \pm 0.03^{\mathrm{a}}$ \\
\hline & & CAMT 21162 & $8.13 \pm 1.24^{\mathrm{a}}$ & $1.03 \pm 0.08^{\mathrm{a}}$ \\
\hline & & HY 91106 & $8.00 \pm 2.34^{\mathrm{a}}$ & $1.07 \pm 0.10^{\mathrm{a}}$ \\
\hline & \multirow[t]{3}{*}{ Vibrio vulnificus } & VV 13009 & - & $0.82 \pm 0.07^{\mathrm{a}}$ \\
\hline & & VV 13010 & - & $0.88 \pm 0.05^{\mathrm{a}}$ \\
\hline & & VV 13011 & - & $0.77 \pm 0.06^{\mathrm{a}}$ \\
\hline
\end{tabular}

Note: Same-strain mean circle diameters for the three egg:rice ratios with different superscript letters are significantly different $(\mathrm{P}<0.05)$.

* Mean \pm standard deviation of three replicates. In control group (without Vibrio inoculation), there was no haemolytic zone and no haemolysis. 


\section{References}

Bowers, J.C. \& Depaola, A. (2010): Relationships between environmental factors and pathogenic Vibrios in the northern Gulf of Mexico. Appl. Environ. Microb., 7621, 7076-7084.

Chiang, M.L. \& Chou, C.C. (2008): Expression of superoxide dismutase, catalase and thermostable direct hemolysin by, and growth in the presence of various nitrogen and carbon sources of heat-shocked and ethanol-shocked Vibrio parahaemolyticus. Int. J. Food Microbiol., 121, 268-274.

Garcia-Arribas, M.L. \& Kramer, J.M. (1990): The effect of glucose, starch, and pH on growth, enterotoxin and haemolysin production by strains of Bacillus cereus associated with food poisoning and non-gastrointestinal infection. Int. J. Food Microbiol., 11, 21-33.

Honda, T. \& IIDA, T. (1993): The pathogenicity of Vibrio parahaemolyticus and the role of thermostable direct haemolysin and related haemolysins. Rev. Med. Microbiol., 4, 106-113.

IuchI, S. \& TANAKA, S. (1980): Catabolite-like repression of extracellular enzyme production in Vibrio parahaemolyticus. Microbiol. Immunol., 24, 803-814.

JANDA, J.M., Power, C. \& Bryant, R.G. (1988): Current perspectives on the epidemiology and pathogenesis of clinically significant Vibrio spp. Clin. Microbiol. Rev., 1, 245-267.

Jongenburger, I., Reij, M.W. \& Boer, E.P. (2010): Factors influencing the accuracy of the plating method used to enumerate low numbers of viable micro-organisms in food. Int. J. Food Microbiol., 143, 32-40.

NishibUCHI, M. \& KAPER, J.B. (1995): Thermostable direct hemolysin gene of Vibrio parahaemolyticus: a virulence gene acquired by a marine bacterium. Infect. Immun., 63, 2093-2099.

Scientific Committee on Enteric Infections and Foodborne Diseases (2011): Food poisoning associated with Vibrio parahaemolyticus in Hong Kong - current situation and recommendations. Centre for Health Protection, Hong Kong SAR. Available at: http://www.chp.gov.hk/files/pdf/Food_Poisoning_Associated_with_Vibrio parahaemolyticus in Hong Kong Current Situation and Recommendations.pdf. last accessed: 2 October, 2018.

Shinoda, S., Matsuoka, H., Tsuchie, T., Miyoshi, S. \& Mizuquchi, Y. (1991): Purification and characterization of a lecithin-dependent haemolysin from Escherichia coli transformed by a Vibrio parahaemolyticus gene. J. Gen. Microbiol., 137, 2705-2711.

Taniguchi, H., Ohta, H., Ogawa, M. \& Mizuguchi, Y. (1985): Cloning and expression in Escherichia coli of Vibrio parahaemolyticus thermostable direct hemolysin and thermolabile hemolysin genes. J. Bacteriol., 162, 510515.

Taniguchi, H., Hirano, H., Kubonura, S. \& Mizuguchi, Y. (1986): Comparison of the nucleotide sequences of the genes for the thermostable direct hemolysin and the thermolabile hemolysin from Vibrio parahaemolyticus. Microb. Pathogenesis, 1, 425-432.

Theethakaew, C., Feil, E.J., Castillo-Ramirez, S., Aanensen, D.M. \& Davies, R.L. (2013): Genetic relationships of Vibrio parahaemolyticus isolates from clinical, human carrier, and environmental sources in Thailand, determined by multilocus sequence analysis. Appl. Environ. Microbiol., 79, 2358-2370.

Tunung, R., Margaret, S., Jeyaletchumi, P., Chai, L.C. \& Son, R. (2010): Prevalence and quantification of Vibrio parahaemolyticus in raw salad vegetables at retail level. J. Microbiol. Biotechn., 20, 391-396.

Wagatsuma, S. (1968): A medium for the test of haemolytic activity of Vibrio parahaemolyticus. Media Circle, 66, 143-151. (In Japanese)

Wang, R.D., Sun, L.J., Wang, Y.L., Deng, Y.J. \& Gooneratne, R. (2016): Pathogenicity of Vibrio parahaemolyticus in different food matrices. J. Food Protect., 79, 288-293.

Wang, R.D., Sun, L.J., Wang, Y.L., Deng, Y.J. \& Gooneratne, R. (2018): Growth and hemolysin production behavior of Vibrio parahaemolyticus in different food matrices. J. Food Protect., 81, 246-253.

Wu, Y. N., WEN, J. \& MA, Y. (2014): Epidemiology of foodborne disease outbreaks caused by Vibrio parahaemolyticus, China, 2003-2008. Food Control, 46, 197-202.

XIE, T.F., Xu, X.K. \& Wu, Q.P. (2016): Prevalence, molecular characterization, and antibiotic susceptibility of Vibrio parahaemolyticus from ready-to-eat foods in China. Front. Microbiol., 7, 549.

This is an open-access article distributed under the terms of the Creative Commons Attribution-NonCommercial 4.0 International License (https://creativecommons.org/licenses/by-nc/4.0/), which permits unrestricted use, distribution, and reproduction in any medium for non-commercial purposes, provided the original author and source are credited, a link to the CC License is provided, and changes - if any - are indicated. 